\title{
Multi-Country Analysis of Causes and Drivers of Child Marriage in Africa
}

\author{
UN Women East and Southern Africa Regional Office in Nairobi-Kenya \\ esaro.publications@unwomen.org
}

The research is funded and led by UN Women East and Southern Africa Regional Office. UN Women is the UN Agency dedicated to gender equality and the empowerment of women. As a global champion for women and girls, UN Women was established to accelerate progress on meeting their needs worldwide. With a vision of equality enshrined in the Charter of the United Nations, UN Women works for the elimination of discrimination against women and girls; the empowerment of women; and the achievement of equality between women and men as partners and beneficiaries of development, human rights, humanitarian action and peace and security. UN Women also coordinates and promotes the UN system's work in advancing gender equality, and in all deliberations and agreements linked to the 2030 Agenda. The entity works to position gender equality as fundamental to the Sustainable Development Goals, and a more inclusive world. It supports UN Member States as they set global standards for achieving gender equality and works with governments and civil society to design laws, policies, programmes and services needed to ensure that the standards are effectively implemented and truly benefit women and girls worldwide. It works globally to make the vision of the Sustainable Development Goals a reality for women and girls and stands behind women's equal participation in all aspects of life. It has invested in its commitment to end all forms of violence including child marriage, Female Genital Mutilation and other harmful practices against women and girls across the globe. UN Women envisions a world where societies are free of gender-based discrimination, where women and men have equal opportunities, where the comprehensive economic and social development of women and girls is ensured so that they can lead the change that they want to see, where gender equality and women's empowerment are achieved, and where women's rights are upheld in all efforts to further development, human rights, peace and security.

\begin{abstract}
This paper is drawn from the findings and recommendations of the UN Women East and Southern Africa led Multi-Country Analytical Study of Legislation, Policies, Interventions and Cultural Practices on Child Marriage in Africa undertaken in 2018. The study focused on Africa as a continent but with a deeper lens on 10 study countries (Niger, Mali, Nigeria, Egypt, Ethiopia, Malawi, Mozambique, Tanzania, DRC and Morocco) that are among those with the highest prevalence of child marriage on the continent despite their high-level national commitments to end child marriage. This paper focuses on the findings of the study, provides analysis, and draws some conclusions about the underlying causes and drivers of child marriage in Africa and in the study countries in particular. The underlying causes of child marriage are common across Africa, and they are anchored in patriarchal societies adhering to discriminatory gender norms that perpetuate gender inequality. This leads to discrimination against women and girls in all spheres of life, including social, cultural, and economic. It forms part of the structural and systemic determinants of the children's, girls' and women's ecology and how they are treated and valued in the society, both in the public and private sphere.
\end{abstract}

Keywords: Child marriage, UN Women, causes and drivers, women and girls, children, culture, religion, society, families, Africa, Niger, Mali, Nigeria, Egypt, Ethiopia, Malawi, Mozambique, Tanzania, DRC and Morocco

DOI: $10.7176 / \mathrm{JCSD} / 49-06$

Publication date:June $30^{\text {th }} 2019$

\section{Background and Context}

1.1 The Global State of Child Marriage

Among the human rights of children stipulated by the Convention on the Rights of the Child (CRC) are: the right to survive; the right to develop to their fullest; the right to protection from harmful practices, abuse and exploitation; and the right to participate fully in family, cultural and social life. By signing the Convention, governments commit to taking "all effective and appropriate measures with a view to abolishing traditional practices prejudicial to the health of the children." Among the practices that were deemed prejudicial were child marriage and female genital mutilation. The International Conference on Population and Development (ICPD) of 1994, adopted a programme of action under which countries committed to undertake measures to eliminate child marriage" and to "strictly enforce laws to ensure that marriage is entered into only with the free and full consent of the intending spouses." The Beijing Declaration and Platform for Action, ${ }^{2}$ also called on countries to eliminate child marriage and to enforce laws that ensure free and full consent. At the Continental level, the Maputo Protocol requires states to ensure that 'the minimum age of marriage for women shall be 18 years. '3 Thus, child marriage refers to a legal or customary union between two people, of whom one or both spouses are below the age of 18 
years. Because child marriage happens when the child/children is/are under the age of consent, the marriage is also described as an early and forced marriage, under any circumstances whether there is apparent consent or not. However, the practice predominantly impacts girls compared to boys due to deep patriarchal attitudes, biological as well as socio-cultural conceptions of maturity and gender inequalities.

Globally, approximately one-quarter of women aged 20-24 years were in a union before the age of 18 years, with approximately one out of thirteen married or in such unions before the age of 15 years. The United Nations Population Fund (UNFPA) estimates that between 2011 and 2020, more than 140 million girls will become children in marriage, meaning that 14.2 million girls will marry annually, or 39000 girls will be children in marriage per day. Furthermore, of the 140 million girls who will marry before they are 18 , fifty million will be under the age of 15 years. ${ }^{4}$ A World Bank Group report (2017) indicates that 41,000 girls are married per day translating to 15 million girls every year confirming the position described by UNFPA. 5,6

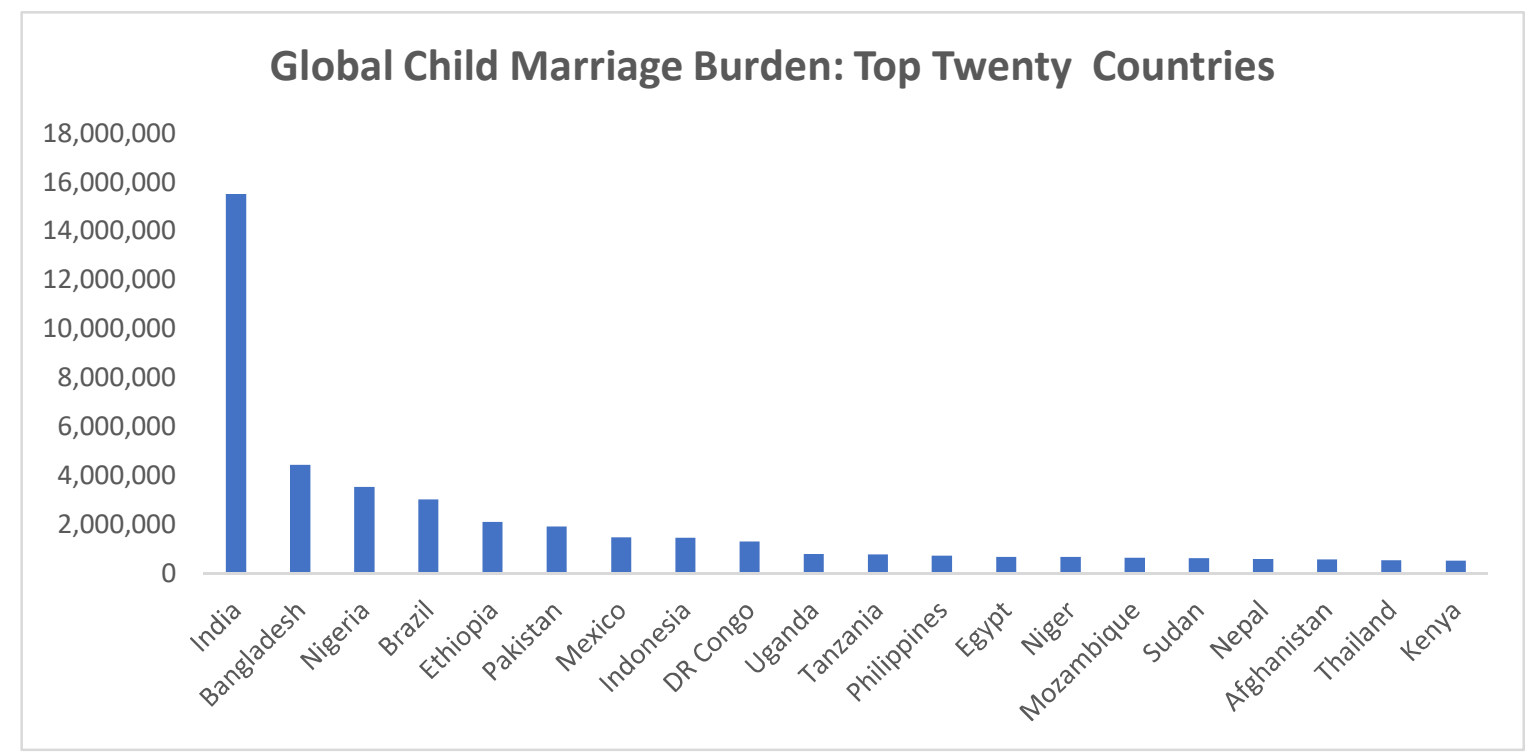

Figure 1: Global Child marriage burden; Top 20 countries

Source: United Nations Children's Fund, The State of the World's Children, UNICEF, New York, 2017.

Global data indicates that child marriage is most common in South Asia and sub-Saharan Africa and the highest global prevalence rates have been documented in $10^{7}$ countries found in these two regions of which Ethiopia, Mali and Niger fall among the study countries. ${ }^{8}$

\subsection{The State of Child Marriage in Africa}

Africa, especially sub-Saharan Africa, is one of the highest child marriage prevalence regions in the world. It is estimated that 125 million (17\%) of the more than 700 million women alive today who married as children live in Africa. Evidence on child marriage prevalence indicates an average of 11.6 per cent and 42.8 per cent girls married by the age of 15 and 18 years respectively. ${ }^{9}$ This translates to approximately 4 in 10 girls married or in a union before the age of 18 years and 1 in 6 girls before the age of 15. All African countries are faced with the challenge of child marriage. Prevalence of child marriage in African countries ranges from high child marriage prevalence countries such as Niger at (76\%), Chad at (72\%), Central African Republic (68\%), Mali at (55\%), Mozambique at $(52 \%)$ and Malawi at $(50 \%) ;{ }^{10}$ to low prevalence countries like Algeria $(3 \%)$. The literature further reveals that more than half of adolescent girls aged 15 to 19 years in Mauritania and Nigeria (one of the countries of study) are currently married and have husbands who are 10 or more years older than they are. Overall, child marriage is more widespread in West and Central Africa (42\%) and Eastern and Southern Africa (36\%). ${ }^{11}$ Figure 4 below shows the 10 highest child marriage prevalence countries in the continent as at $2015 .^{12}$

Africa has strong policy and legal frameworks in advancing the Rights of the Child and gender equality. For instance, the Protocol to the African Charter on Human and Peoples' Rights on the Rights of Women in Africa (Maputo Protocol) and African Charter on the Rights and Welfare of the Child contain provisions specifically aimed at ending harmful practices including child marriage and these combined with interventional initiatives, such as the African Common Position and the African Campaign on Ending Child Marriage, which are concretely expressed in Goal 18 of the continent's Agenda 2063. However, child marriage remains a persistent problem across the continent of Africa. It is projected that by 2050, the number of children that are married before the age of 18 years will double if nothing is done to eradicate child marriage. ${ }^{13}$ From the study, Niger, Mali, and Mozambique 
have the highest percentages $(48 \%, 46 \%$ and $40 \%$ respectively) of girls having their first children by 18 years. However, Mali tops all the countries of study in the number of girls who give birth to their first child by the age of 15 years.

\section{Ten child marriage hotspots in Africa:}

\section{Countries with the highest child marriage rates.}

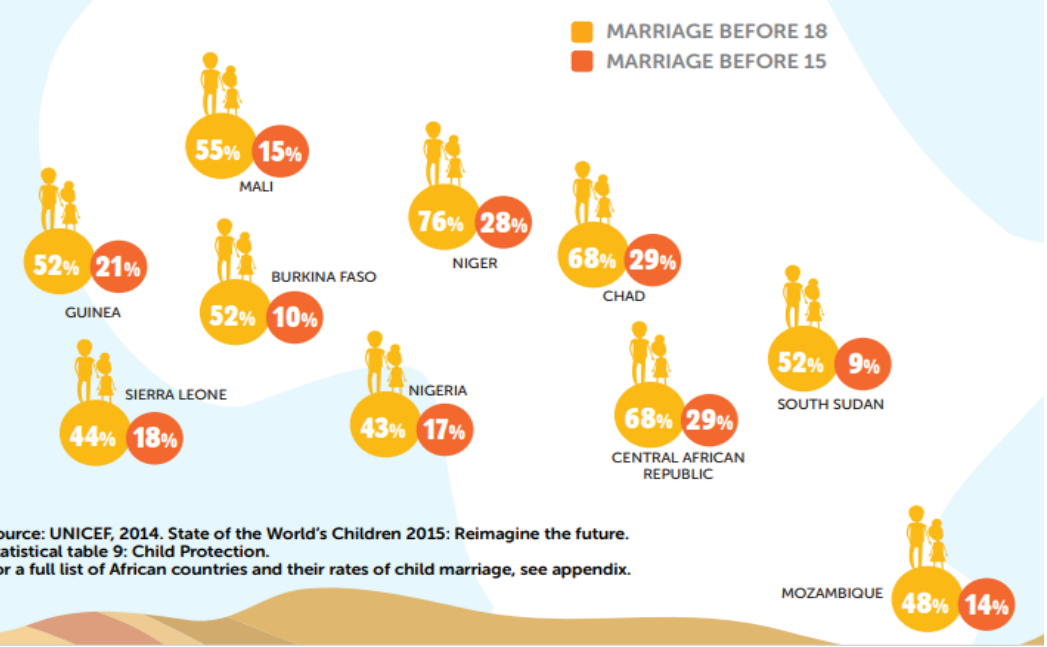

Figure 2: The ten highest child marriage prevalence countries in Africa

Source: State of the World's Children 2015: Reimagine the future1.3 Effects and Consequences of Child Marriage in Africa

\section{Analysis and Findings}

The study identified three layers of causes and drivers for child marriage in Africa: Enablers, Motivators and Drivers. The first layer, enablers, consists of factors that form the structural ecology within which child marriage is either enabled and facilitated or condoned and justified. These enablers include structural gender inequality built on a patriarchal system of beliefs that defines the position and status of women and girls as subordinate to men and boys. This results in pervasive feminisation of poverty at household level and viewing women as property not as people with full human rights. Where armed conflict and insecurity exist, this creates further risks for girls by driving societal beliefs that marriage is a form of protection for girls and their families. Further, social inequality leads to lack of prioritisation of girls' education making girls and their families believe that marriage is an option where education is not available. Religious teachings and negative cultural practices continue to fuel child marriage by affirming men's control of women's autonomy, integrity and particularly girls and women's sexuality.

Macro-level determinants such as; low education levels and religious teachings and systems which rival the legal systems are also enablers. The core role of enablers is their implicit creation and sustaining of an environment within which early marriage is an option for families and children.

The second layer is made up of intermediate level conditions or factors that essentially act as motivators of child marriage. These factors facilitate justification of child marriage and other practices that reinforce child marriage and girls' acceptance of the practice, for example, negative elements of the rites of passage, FGM, betrothal, virginity preservation and the perception that child marriage assists families to escape poverty. In addition, the absence or the presence of contradictory laws and the lack of implementation and enforcement of laws create conditions conducive to continuity of child marriage.

The third level of factors consists of micro level conditions that affect families and the children directly. These are the direct drivers because they make child/early marriage the only option for survival. These are: lack of basic services in communities such as education including age appropriate comprehensive sexuality education; lack of social protection for the most vulnerable people and families; lack of health services and lack of human centred security. As a result, direct drivers such as teenage pregnancy, lack of basic means of survival, sexual violence, devaluation of unmarried women, family honour, and stigmatization of delayed marriage drive girls into child marriage. For instance, in Nigeria, there is anticipation of pride price as a source of income to relieve of financial burdens of poor households. The actual amount of bride price is again tied to the condition of the bride thus creating a cycle between the drivers and the motivators because, since girls cannot inherit family property, marriage offers the best way out. ${ }^{14}$

The following drivers (summarized in the graph below) were identified by respondents as the everyday drivers and motivators that spur child marriage in their communities. 
Scale of 1 to 5 ; where $(1)=$ strongly disagree; $(2)=$ disagree; $(3)=$ neutral $(4)=$ agree $(5)=$ strongly agree

\section{Causes/Drivers/motivators of Child marriage in community}

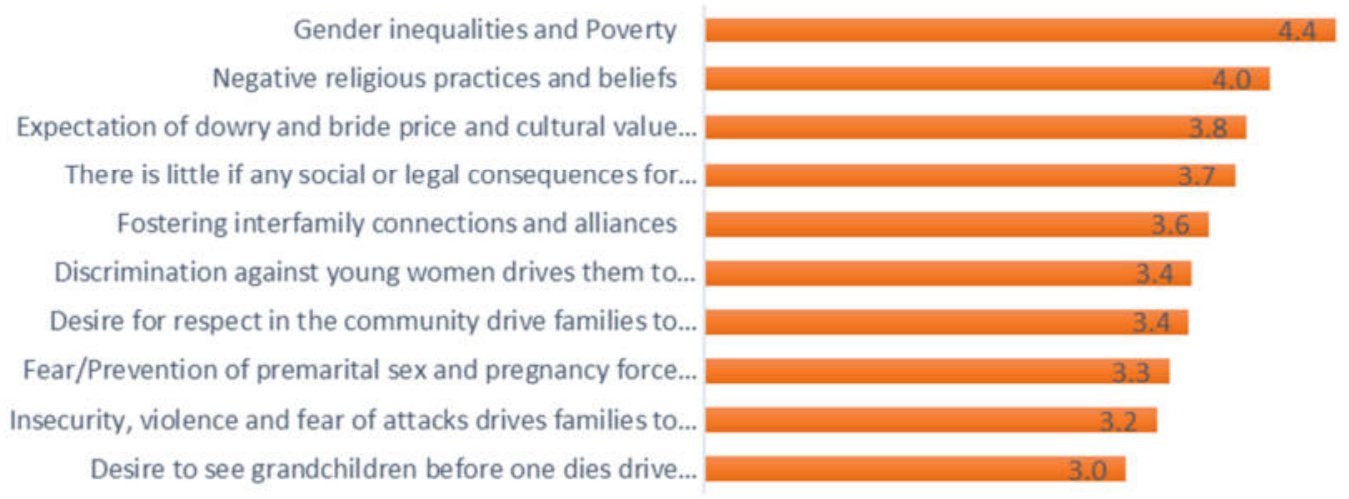

Figure 3: Identified community drivers and motivators

Source: UN Women field data (2018)

\subsection{Gender inequality}

The study affirms that gender inequality is prevalent amongst all the study countries and provides a fertile ground for discriminatory practices against women and girls. It limits a girl's and woman's opportunity to fully participate in decision making on matters important to them including those related to her education, health, participation in the economy, and intimate relationships and marriage including the decision whether or when to marry and whom to marry. In Tanzania, for example, married women have less control over their lives than married men do. As of 2014, it was reported that two out of five married women do not participate in decision making regarding their own healthcare. In Mara region of Tanzania, only $8 \%$ of women participate in household decision- making while in Kilimanjaro region the figure is higher at $64 \%$.

While child marriage affects all children, it is especially prevalent among girls in rural areas and poor urban communities that lack: access to schools and quality education or walking long distances to school; access to health care, especially adolescent sexual and reproductive health services; and access to employment and livelihoods opportunities. Unfortunately, there is only limited allocation of resources towards gender equality and related issues, including ending violence against women, and ending child marriage, and other harmful practices. This limits the implementation and enforcement of existing laws and policies on ending gender inequality as a driver of child marriage as a consequence.

As explained above gender inequality is the underlying cause and driver of child marriage and is embedded in all the other drivers discussed in the report.

\subsection{Traditional and cultural practices}

When a girl is born, she is celebrated as a wife/bride from childhood while boys are celebrated as heroes and fathers of nations due to social and cultural norms. As a result, child marriage is a readily accepted cultural practice among most communities in Africa even where it goes against positive traditional values and is prohibited by the law. Many families perpetuate the practice in the belief that it is in their best interest and that of the child. It is widely viewed as a way of improving the social and economic status of the girl's family through receipt of a bride price from the husband's family. Many girls also view marriage as an easy route to escape poverty. However, in fact, child marriage creates a vicious cycle of poverty for the girl and her family. Cultural rites of passage that girls undergo (sexual initiation) expose them to the risks of teenage pregnancies which, once they happen are not accepted by the community. Child marriage therefore is regarded by the girl's family as a pre-emptive way of safeguarding family honour.

It is important to note that girls and their families are also expected to bring material contributions. It is concerning that married girls are expected to be available for sex, to have children, and to provide unpaid domestic and care work, all of which go unrecognised and are thereby made invisible.

2.1.1 FGM and rites of passage

The study reports that harmful traditional practices such as female genital mutilation/cutting (FGM/C) drives child marriage across all the ten countries of study. FGM/C is used as a rite of passage from childhood to adulthood, a 
signal that a girl is ready to marry across seven out of the 10 countries studied. A girl from a practising community is not considered ready for marriage until she has undergone FGM/C irrespective of the age of the girl. There are many reasons behind female genital mutilation which includes controlling the girl's sexual desire. It is a violation of the rights of women and is embedded in cultural beliefs on sexuality control of women.

In Tanzania for example, the national prevalence of FGM/C is currently $14.6 \%$ as of 2014 . A 2016 survey on drivers of child marriage ${ }^{15}$ carried out by the government of Tanzania in collaboration with research institutions and NGOs ${ }^{16}$ showed that FGM/C was one of the key drivers of child marriage in Mara, Manyara, and Dodoma regions. Similarly, statistics in Egypt indicates that approximately 90\% of women aged 15-49 and who are in a union are circumcised; this is replicated in Ethiopia where $65 \%$ of women aged 15-65 years have experienced FGM. In Mali, amongst Malian women aged 15-49 years, 91\% are circumcised and sadly, 70\% of girls aged 0-14 years are already circumcised in Mali, while 83\% aged 10-14 years have faced FGM/C in their lives. Cultural practices in Malawi facilitate the entry into marriage of young girls upon graduating from the puberty rite of passage, a rite that 'encourages' them to engage in their first sexual intercourse with an older male, for the main reason of 'dusting off' or 'clearing the dust' thereby making them ready for marriage as young as 10-12 years of age. $^{17}$

Traditional dances during rites of passage are often not age appropriate, especially as observed in Tanzania, and contribute to child marriage through creating a belief that girls participating are ready for marriage. This was observed specifically in Shinyanga, Tabora, Pwani, Lindi and Mtwara, while initiation rites (Unyago) were cited as drivers in Lindi, Mtwara, Dar es Salaam and Pwani. ${ }^{18}$

2.1.2 Dowry and Bride Price

The traditional underlying value of dowry and bride price was a customary process of formalising a marriage, characterised by the exchange of gifts or money or payment of livestock. It also brought family respect. The quantity of bride price varies across traditional communities, with notable recent trends of equating levels of education and virginity with the amount of the bride price. Women across Africa are generally valued on the quantum of the bride price they can attract. Accordingly, families with many girls are considered wealthier than those with few girls. In Tanzania, families in Shinyanga and Manyara regions highly value "mahari" (dowry). The payment of bride price comes with reciprocal expectations on the married girl in relation to fertility and child bearing as well as the contribution of her labour into the new household. There is a gender critique which argues that the current practice of dowry and bride price is resulting increasingly in the commodification of girls. In cases where an older couple has no child, the blame is put on the woman and, frequently, culture practice requires her to agree to her husband marrying a younger girl for the purposes of child bearing, provision of labour, and preservation of wealth. In other cases, an older woman actually marries a younger girl and pays bride price as a wife. This was the case in Tanzania.

Case Study 1: Quest for Social Prestige is encouraging child marriage in Shinyanga

Another major cultural driving force of child marriage is the extravagant consumption and cost of ceremonies that is not necessarily connected to family poverty. One of the girls (17 years) interviewed in Shinyanga region in February 2018 said that, her father had more than 30 cows at the time a plan of her marriage was undertaken in 2016. There were also no huge family expenses as she is the second to the last born and other siblings were already earning an independent living in their homes. Therefore, the father needed more cows as part of social prestige. He married a second wife after sending off his second daughter some years back. Probably, a dowry from this survivor could have been for the same purpose - demonstrating social stature per Sukuma culture.

Source: UN Women field data (2018)

In DRC, communities value the position of a 'wife' as a person who deserves to be loved, cherished, and protected. Social norms place a high value on a girl who is getting married and this fuel the high bride price asked during contracting of unions. Such perceptions fuel child marriages. In addition, this perception forces even boys to leave their education in search of employment to care for children in marriage. This value is what singles out the girls as vulnerable candidates to be used to settle family debts. Communities' failure to accept back, into the community, girls who have children out of wedlock as a result of slavery or rape also fuels child marriage. Forcing such girls to get married to their rapists or captors further encourages the practice as a form of punishment.

2.1.3 Parental participation and decision-making

The study found out that the main decision makers on matters of marriage are men. The Moudawana establishes the principle of co-responsibility and equal rights and duties between the two spouses. It is one of the major reforms that the new Family Code brought in 2004. In Morocco, Mali and Egypt, women are rarely involved in any marriage discussion. Their role is to receive instructions from the male family heads. On the same note, DRC communities marry their children from as early as age of 15 years while $95 \%$ of girls in Ethiopia were married through forced marriages arranged by their parents. The situation in Tanzania is no exception with women only 
making decisions in the total absence of any male member of the family. Girls in Malawi are left with no choice after 'Mpenjele Kuno' (a practice where a man who cannot attract a woman for marriage resorts to kidnapping) as they are returned to their kidnappers by their parents.

2.1.4 Family Honour and Virginity

The high value that communities place on virginity before marriage makes the practice of child marriage an acceptable means of preserving family honour. This results in forced marriage of adolescent girls in cases where they are perceived to be having a sexual relationship or have experience of teenage pregnancy. Virginity testing is prevalent in some communities for the same reasons. This may result in girls being subjected to marriage, even marriage to their rapists as mentioned in the case of DRC above. For instance, Islam which is widely practised in many parts of Egypt, Morocco, Mali, and Nigeria, has strict religious taboos regarding female sexuality and purity. Such taboos bar girls and women from having sex with men of their choosing as well as preventing children in marriage from leaving their husbands. Children in marriage who flee their husbands are punished harshly including being killed by one of the bride's birth family member. ${ }^{19}$ While some religions condone child marriage in some communities, child marriage is viewed as a quick and preferred way of settling societal feuds.

The study data showed that Mali has culturally and ethnically diverse people mostly of Arab-Berber origin who make up $99 \%$ of the total Mali population. However, in the entire West Africa, Mali is one of the many nations with deeply entrenched discriminatory cultural practices against girls and women. The culture values family honour, manifest through the sexual purity of their daughters, embraces male chauvinism and celebrates dominance over females. Additionally, the most widespread religion in Mali is Islam, which has strict religious taboos with regards to female sexuality purity and marital issues. According to Islamic religious beliefs, girls and women have no rights whatsoever to engage in premarital affairs with men of their choices. Family honour is an entrenched cultural value that has a direct link to child marriage, particularly, the rising numbers of children in marriage. Based on the Malian family codes, it is hard for girls to escape child marriage and women/girls also find it almost impossible to divorce after marriage due to the long divorce process, which includes losing financial support.

\subsubsection{Poverty}

The World Bank highlights the feminisation of poverty phenomenon to demonstrate the extent to which women are disproportionately affected by poverty. This is due to patriarchal and negative cultural practices that perpetuate gender inequalities in wealth accumulation, ownership and control of resources such as land, as well as unequal access to opportunities in education and employment that are key to reducing chances of living in poverty. For example, in Nigeria, families favour boy child education while discouraging daughters from attending school on the basis that girls will be married and leave their families.

In a majority of the study countries, poverty was found to be one of the direct drivers of child marriage giving rise to the belief that marriage is an escape from poverty by the girls and their families through payment of dowry and bride price and results in shifting the burden of caring for the girl from her family to the family where she is married.

In Malawi for example nearly $53 \%$ of the inhabitants live below the poverty line and thus some families see child marriage as a means of survival. Similarly, in DRC, Mozambique and Niger, families use their daughters to "settle debts" by marrying them off or giving them out as sex slaves to their rich creditors. In all these cases, nearly over one half (DRC $70 \%$, Mozambique $46.1 \%$, and Niger $80 \%$ ) of the population is under the poverty line and are rural-based. This is also evident in Morocco and Egypt where wealthy businessmen suitors from Saudi Arabia and the Gulf States enter the country and pay as little as $\$ 500$ to marry children. ${ }^{20}$ However, in a country like Mali there is a strong belief about the preservation of family honour which intersects with the high levels of poverty (at $44 \%$ ) and thereby creates increased likelihood of child marriage.

In addition, poverty is a mass phenomenon in Mozambique, affecting almost half of the population, and those not in the category of poor are close to the poverty line. ${ }^{21}$ Ranked as one of the world's poor countries, $70 \%$ of the population resides in rural settings relying heavily on farming, which is mainly done by women, for their daily subsistence. Girls' value is tied to performing domestic and care work and providing family continuity, as usually within 15 months of marriage, a girl will have given birth. Girls are socialized to be subordinate towards their husbands and to respect older people as they transition into adulthood and gain experience in marriage. Traditions are used to formalize child marriages, with modern religion being used as a ceremonial event to solidify the marriage though the formal legal process.

\subsubsection{Harmful Religious Practices}

While religious values are expected to be life affirming, grounded in the ethos of love and protection of the weak and children in society, the major religions, together with their institutions across the study countries, have a strong interface with cultural practices and in fact reinforce some values that drive and perpetuate child marriages. In many communities across these countries, it plays both sides of the child marriage situation in terms of being both a driver and a deterrent to child marriage. Nonetheless, the study identified significant potential for harnessing religion and culture to address child marriage. For example, Malawi has shown how diverse agencies have engaged 
Paramount Chiefs from various hotspots e.g. with Senior Chieftainess Kachindamoto, in legal and social empowerment. The Chief has been instrumental in establishing 'by-laws' and setting up community parliaments at community levels that aim for deterrence of child marriages and promoting girls' education with the aim of keeping the girl in school longer. This is expected to delay marriage and gives the girl more opportunities for selfadvancement through education and skills training. Through Senior Chieftainess Kachindmoto's intervention in Malawi, she successfully rescued more than 2,500 girls from child marriages. Most of these girls are back with their families; some are back at school courtesy of the return to school policy for teenage mothers; while some are stuck at home with no vocational training skills due to inability to afford school fees. In Ethiopia, religion determines the differences in the types of marriages undertaken, e.g. among the Orthodox Christians, $81 \%$ of girls got married through arranged marriages compared to only $62 \%$ of Muslim girls. ${ }^{22}$

Whereas, on the other hand, religion offers a system within which interventions can be anchored, with its attendant services in communities on social issues like education, health, food security, water and sanitation, it also, on the other hand, often provides normative frames for perpetuation of child marriage and other harmful traditional practices. For instance, Islamic preachers in Nigeria argued that under Islamic doctrines, girls' maturity is defined by 'physical appearance; ... when a girl starts menstruation - she is matured'. In most cases, the study found that religion is more often than not a supportive frame for persistent cultural traditions within a particular community and regularly deployed to justify child marriage as a protective measure for ensuring purity, fidelity and honour.

Case Study 2: Religion as a driver of child marriage in Niger Source: UN Women field data (2018)

According to a key informant from Niger, different interpretations of Islamic scriptures provides three bases for child marriages: The marriage of the Prophet Muhammad to his wife Aisha at six years old; the invocations that giving out your daughter as a gift in marriage assures blessings in the afterlife; and the conviction that marrying off a girl shields her from premarital sex, promiscuity and pregnant outside marriage. Interpretations and perspectives have deeply entrenched the practice of child marriage as they are considered as central teachings in Islamic scriptures and contravention of these teachings is considered as acting against the holy teachings.

Such logic was found to exist in both Christianity and Islam; these two dominant religions in Africa that emphasize the sanctity and honour of married life, and the subservient position of women in marriage. Neither provides a clear statement of the appropriate age for marriage, instead making convenient deference to customary and civil laws in the countries of study. This convenient deference provides strategic loopholes through which religion, in practice, plays both sides of the child marriage laws - they can claim to marry only consenting mature brides and grooms, while leaving the definition open for the parties involved. In extreme cases religious-framed conflicts have led to abduction and forced marriage of girls in Nigeria (Boko Haram -Islamic) and in Uganda (the Lords' Resistance Army - Christian).

In Ethiopia, religious values lay great emphasis on a girl's purity and virginity and therefore a girl and her family are stigmatized if they are seen as 'impure' or 'too old'. ${ }^{23}$

The study established that half of the population in Nigeria is Muslim, 40-45\% is Christian, and 5-10\% practice indigenous religious traditions. ${ }^{24}$ The North is largely Muslim and the South is largely Christian. ${ }^{25}$ It is true that Islam is deeply entrenched in the North, with many different strands and beliefs represented, from widespread affiliation with Sufi brotherhoods, to Salafi interpretations of Islam that reject Sufism, small Shi'a communities, and various interactions with indigenous beliefs ${ }^{26}$. Christianity, predominantly comprising Catholicism and Anglicanism, prevails in the Southeast but South-western Nigeria is mixed, with substantial Muslim, Christian, and traditional religious communities ${ }^{27}$. There is a sizable Christian minority in several northern states (mostly migrants from the southern areas of the country), although this population is shrinking as Christians flee from violence. The "Middle Belt," an area encompassing six states, is populated largely by ethnic minorities and is also highly religiously diverse ${ }^{28}$. These diverse religious affiliations have varied impacts on child marriage with Muslim communities seen to contribute to the highest prevalence and thereby signifying the role of religion in child marriage.

Mozambique has a mixed religious profile with approximately one-third being Christians and the main denomination being the Roman Catholic. The northern regions practice Islam. African traditions are also practised especially belief in the spirit of ancestors who affect the lives of the living. Often, modern religion and African traditions are practised together interchangeably. Beliefs include an all-powerful God as well as spirits.

There is not current profile of religious affiliation in Tanzania as the same was eliminated from the national census since $1967 .^{29}$ It is however estimated by religious leaders and sociologists that Muslims and Christians are approximately equal in size, each accounting for $30-40 \%$ of the total population, with the remainder consisting of practitioners of other world faiths, practitioners of indigenous religions, and people of no religion. ${ }^{30}$ Neither 
Christianity nor Islam in Tanzania spells out the age of marriage. It should be noted that religious groups have the power to effect change in perceptions, practices and negative cultural norms in communities. If they are involved, they are likely to be listened to. For instance, in Tarime, study participants mentioned that Seventh Day Adventist members do not perform FGM on women, showing the power of religion in influencing social and cultural practices. ${ }^{31}$ The regional disparities in child marriage, cultural and geographical differences across the country determine the forms in which living arrangements in child marriage take shape.

Mali is made up mainly of people of Arab-Berber origin. They are the majority in terms of the population, making up approximately $99 \%$ of the total population. Nonetheless, the country is also inhabited by other communities such as Christians and Jews who constitute the remaining $1 \%$ of the population. Of great significance is that no single religion promotes child marriage in Mali, unlike most Arab countries where child marriage is more or less a common phenomenon. However, the religions have different perspectives in approaching sexuality and social relations. The most widespread religion in Mali is Islam, which has strict religious taboos with regards to female sexuality purity and marital issues. By contrast, many religions do not put the same emphasis on male sexuality as they do on female sexual purity and lifestyle in general. According to Islamic and Christian religious beliefs, girls and women have no rights whatsoever to engage in premarital affairs with men of their choice.

In other words, the country is homogeneous in both culture and religion. As in many other Arab states like Egypt, no religion promotes child marriage outright in Morocco but each religion approaches sexuality and human relations from different perspectives. Islam, which is widely practised in many parts in Morocco has authoritarian religious taboos regarding female sexuality and purity with little concern about males and their lifestyles. For instance, Muslim girls and women cannot have premarital sexual relationship with men of their choice.

While Articles 16, 19, 20 and 21 of the Moroccan Family Code were significant advances in the approaches to the persistent practice of customary marriage, particularly in rural areas, various exceptions have limited their efficacy. While they focused on eradicating out-of-marriage pregnancies they placed no checks on the legal minimum age of such pregnancies. Accordingly, the practice of legalizing customary marital unions has created a leeway for child marriage practice in Morocco. In practical terms, the government is only responding to the constraints imposed by prevailing practices and mentalities to the detriment of the protection of the universal rights of children, particularly girls. Even after marriage, girls in marriage find it hard to get a divorce due to lengthy court processes and conditions including forfeiture of the alimony. Even though no particular religion in Morocco directly associates with child marriage, the practice enjoys a strong backing from both customary and religious policies and practices that accord it a lot of perceived benefits. In fact, different religious organizations manifest the practice in various forms. For instance, Islam widely practiced in many parts of Egypt, Morocco, Mali, and Nigeria has strict religious taboos regarding female sexuality and purity. Such taboos bar girls and women from having sex with men of their choosing as well as preventing children in marriage from leaving their husbands. As a result, children in marriage who flee their husbands are punished harshly including possibly being killed by a member of the bride's birth family. ${ }^{32}$ While some religions condone child marriage, while in some communities, child marriage is seen as a quick and preferred way of settling societal feuds.

The study found out that many marriages in the contemporary West Africa are polygamous. This practice is mainly prevalent in the rural areas as compared to urban regions. In polygamous marriages and particularly the polygyny form, husbands are usually much older than their wives. ${ }^{33}$ This replicate what happens when children are married off. Reports indicate that over one-third of child marriages end up as polygamous unions and mostly as second or third wives. ${ }^{34}$

Majority of marriages reviewed by the study are either religious or traditional and are rarely civilly registered, a situation which complicates legal solutions for child marriage. Religion and traditions have influenced certain Islamic associations and some influential people to oppose legislative and policy changes that would offer greater protection against the practice of child marriage. In Niger, for example, the resistance has previously hindered initiatives like the adoption of a family code, and a law to protect young girls at school, all aimed at fighting child marriage.

Additionally, various religious holy books are not clear on the minimum age for marriage particularly for women and girls. Both Christian and Muslim majority countries under this study demonstrate the lack. For instance, Mali, Niger, Egypt and Morocco are approximately 90\% Muslim, whose source of laws, Quran and Hadith are not clear on the minimum age for marriage thus leaving room for various clerical and scholarly interpretations and leaving the major decision on child marriage within the direction of their congregants. Similarly, there is no clear determination of the minimum age for marriage among Christians and Jews as their holy books do not specify one. In Nigeria, the domineering influence of parents and elders, within the context of strong religious norms based on an interpretation of the Islamic marital code, fuels child marriage. Amongst these norms is the belief that a girl child is fully matured for marriage and should be married off before or upon reaching puberty, the sure sign of which is the commencement of the menstrual period. ${ }^{35}$ It is without doubt that specific 
interpretations and understanding of patriarchal culture have been a significant catalyst for child marriage in the Northern Africa Arab region. In Ethiopia, religious values lay great emphasis on a girl's purity and virginity and therefore a girl and her family are stigmatized if they are seen as 'impure' or 'too old' ${ }^{36}$ Primary data established that the customs and traditions of Niger are deeply entrenched and closely integrated into the Islamic religion which is practiced by $90 \%$ of the population. This was so much so that the Civil Code which was developed under colonial rule and which is still observed in present days did not gain legitimacy with the majority Islamic populace. This led to the enactment of the Mendel Decree of 1939 which accepted the customs and culture of the people as an integral part of the laws of the land. Islamic interpretations of the marriage of Prophet Mohamed to Aisha while she was six years old have cemented the customs and traditions of Niger and are taken as one of the strong justifications for child marriages. Religion and traditions have influenced certain Islamic associations and some influential people to oppose legislative and policy changes that would offer greater protection against the practice of child marriage ${ }^{37}$ The resistance has previously hindered initiatives like the adoption of the family code, a law to protect young girls at school, all aimed at fighting child marriage. ${ }^{38}$

Case Study 3: Polygamy preying on underage Nigerian girls

At the age of 15 years, Salamatou was married as the third wife to her husband who was much older than her. Her husband approached her family with the intention of marrying her. Since her father had passed on earlier, her mother consulted with the brother of her late husband, Salamatou's uncle and the wedding was arranged. Her husband and his family paid dowry of an equivalent of USD 600. Salamatou who has never been to school says that marriage saved her from engaging in premarital sex, promiscuity and from picking bad unacceptable values. She believes that as a Muslim girl, the marriage helped her maintain a good name for herself and her family and helped her keep her dignity. However, she understands that child marriages put so many teenage girls like her at risk. For instance, she had complications while delivering the first of her three children. Though she made it out alive, she knows of many other girls her age who have lost their lives at child birth or ended up with obstetric fistula due the difficulties of giving birth. The aspect of sharing her husband with 2 of her co-wives is a source of distress for her and sometimes things get out of hand and she feels so disenfranchised in the relationship. Her advice to girls her age is to wait and not enter into marriage before completing their education and learning a skill.

Source: UN Women field data (2018)

Marrying off girls in many parts of Morocco is a commonplace phenomenon. The practice enjoys a strong backing from both customary and religious policies and practices that ascribe to the child marriage many perceived benefits. For instance, the different interpretations of the sacred texts (with Muslim texts being the most dominant in the country) and culture strongly advocates for human procreation and a high number of children. Accordingly, marrying at a tender age (under 18 years) provides more room for giving birth to as many children as possible.

2.1.6 Legal gaps

Many countries in Africa have conflicting customary, statutory and religious provisions surrounding child marriage and marriage in general. Morocco's Moudawana (the Family Code) which was amended in 2014 to stop child marriage still has gaps that enable child marriage. Specifically, Articles 20 and 21 allows a judge to marry an underage child (below the legal age of 18 years) by handing down a well-substantiated decision explaining the interest and reasons justifying the marriage. This loophole fundamentally perpetuates the practice of child marriage as it creates an environment that encourages child marriage.

\begin{tabular}{|l|r|r|r|}
\hline Year & Boys & Girls & Total \\
\hline 2007 & 379 & 38,331 & 38,710 \\
\hline 2008 & 308 & 39,296 & 39,604 \\
\hline 2009 & 174 & 46,915 & 47,089 \\
\hline 2010 & 438 & 44,134 & 44,572 \\
\hline 2011 & 326 & 46,601 & 46,927 \\
\hline 2012 & 106 & 42,677 & 42,783 \\
\hline 2013 & 92 & 43,416 & 43,508 \\
\hline
\end{tabular}

Figure 4: Applications for premature marriage 2007-2013

Source: UNICF, $2015^{39}$

Similarly, Article 16 of Moudawana allows a court petition to officialise a marriage that was not officially registered in due time within an interim period not to exceed five years from the date the law went into effect. In 2013, it was noted that marriage of teenagers in Morocco not only increased from 18,341 to 39,031 but also that 
approximately 16,426 of them were under 16 years old. This prompted a quest for a policy change to ensure that no person under the age of 16 years gets married, not even through the Family Affairs judges. Unfortunately, the proposal is yet to be actualized into law due to lengthy legislative processes in the country. In fact, this debate was reawakened in February 2018 by the committee on Justice, Legislation and Human Rights in the Chamber of Advisers.

In Tanzania there are obvious conflicts of laws between the Law of the Child Act 2009 and the Law of Marriage Act 1971. This is because the marriage act law sanctions the marriage of girls as children, while requiring boys to first be adults as reflected in section 13(1) "No person shall marry who, being male, has not attained the apparent age of eighteen years or, being female, has not attained the apparent age of fifteen years." In addition, a court may give leave for the marriage of a fourteen- year-old girl, if the court, according to section 13(2) "is satisfied that there are special circumstances which make the proposed marriage desirable." This complicates enforcement of both laws especially with regards to child marriage. For instance, a police officer at Shinyanga told the study team that, they normally rely on the Education Act 1978 because that is 'straight forward' unlike the Law of the Child Act 2009 which fails to make a clear direction on this matter. However, according to the police officer, a dilemma arises when a child involved is not a student. The conflict of laws between the child and marriage laws has remained unresolved at the time of this study despite a High Court decision of 2016 ordering repeal of the marriage law's section which allows marriage of teenage girls. Government lodged an appeal to the Court of Appeal of Tanzania and the case is still pending. The study further notes that the Constitution of Tanzania with its amendments is silent about the age of a child and neither provides for the age of marriage not the definition of a child. The Constitution provides for the age of majority in relation to voting rights under 5 (1) which states that every citizen of the Untied Republic who has attained the age of eighteen years is entitled to vote in any election held in Tanzania.

It is important to note that even where laws and policies on ending child marriage are strong, implementation and enforcement remains a challenge due to the persistence of negative cultural and traditional norms, values and practices that continue to perpetuate gender inequality and the low status of women and girls in a society and in the family. In Ethiopia, for instance, despite the legal age for marriage being 18 years for both boys and girls, there is rarely enforcement of such laws thus leading to lack of prosecution of perpetrators and hence entrenchment of this illegal practice. Additionally, national registration of births, deaths, marriages and divorces is dwindling thus making it cumbersome for authorities to prove that a girl is underage.

Further, the study reports that in Africa, enforcement of laws is further compromised by corruption, lack of accountability by responsible government officials, armed conflicts and lack of prioritisation to invest adequate resources - to drive the implementation of laws and policies. Such investments can be utilized for awareness creation; capacity strengthening for law enforcement and the judiciary; referral systems; strengthening the role of the civil society, traditional and religious leaders and authorities in implementation laws; and laws, policies and interventions aimed at ending child marriage. Corruption is one of the issues that is reported to hamper effectiveness and efficiency of interventions with agencies and governments alleged to have diverted funds meant for child marriage interventions and hampering prosecution mechanisms for perpetrators of child marriage. Conditions and practices such as corrupt officials and a negative socio-culturally/religiously influenced judicial officers affect compliance and enforcement of law. Specific country and community conditions and practices in this regard make enforcement of laws and policies difficult and compromise the capacity of the structures charged with monitoring and implementing the laws.

\subsubsection{Political instability, insecurity and the humanitarian situation}

Political instability has remained a common phenomenon in Africa for centuries. Particularly, the Arab Spring that swept through MENA countries across the world created political instability, insecurity and a parlous humanitarian situation in Egypt. Women and girls faced sexual harassment, rape and kidnapping. Political and civil feuds also generated the need for both familial and interfamilial collaborations, often sealed through child marriage. In most cases, the girls are married off to influential elders or military leaders on the assumption that this will guarantee the girl and her family protection, brokering truces and forging bonds in the community. The reality is that it actually subjects girls to sexual abuse and harassment by the men who marry them and therefore this cannot be a form of protection to the girls being married off. In Morocco, however, various matches and protests mushroomed in northern parts after the Arab Spring to put pressure on King Mohammed VI to transfer some of his powers to the Prime Minister and this yielded fruits in 2017 when the Prime Minister acquired some executive powers. ${ }^{40}$ Additionally, militia and armed groups have abducted girls below 18 years in Nigeria and DRC who then face various forms of violence including but not limited to child marriage, rape, slavery and battering. Beyond the high death toll and population displacement in DRC, the wars have caused tremendous social and psychological trauma for women, young girls and boys who have been subject to physical and psychological atrocities including rape, torture, humiliation and alienation from their communities. ${ }^{41}$ On the same note, a group named Boko Haram has launched campaigns of violence in Nigeria that have lasted for years with the high profile incident of 2014 where over 200 schools girls were kidnapped: fears are rife that a majority of the girls have been forced into marriage by 
their captors.

"A girl called Anita Ami (not her real name) was on her way to her uncle's home in Gao City in the month of June 2012, she met two men on a motorbike who stopped her. She reported that she had no choice since the insurgents were armed and threatened to kill her. She reported that, the two men held her baby in turns as they repeatedly raped and left her in the bush."

"A local journalist and human rights activist, Ami Idris sought for safety by hiding in her house. She also reported that not all were fortunate enough to find a place to hide. Idris narrated her ordeal and said that everyone has a sister or cousin who underwent instances of rape. In her report, she reiterated that daughters were assaulted before their family members such as fathers and were completely traumatized by the experiences."

According to her, many residents reported that the perpetrators of the crimes were allegedly members of the National Movement for the Liberation of Azawad (MNLA). Although Idris continued to report that militant group were the ones who committed the abuses, she had unfortunately forced her to quit her job as a radio host since the Islamic faith, according to the perpetrators, does not allow women's voices on the radio.

2.1.8 Access to Education and Illiteracy

Low education levels in many countries have fuelled child marriage across the 10 countries of study. In Malawi, for example, the transition rates to high school stand at 36\% (35\% for boys and $37 \%$ for girls) as at $2014^{42}$ and get even worse for higher education with only $1 \%$ of youths aged 15-24 years being enrolled ${ }^{43}$ in Malawi, and fewer students obtaining employment upon completion of learning. Girls who have completed school and are jobless are held in low esteem. This makes many poor families not see the importance of education and makes it even more difficult for the girl child to be given a chance to proceed further in education. Similarly, Egypt has not sufficiently invested in girl child education and health care besides having few empowerment programmes for girls and women in general. Whereas there is some improvement in the enrolment of girls in school in Ethiopia, the commitment to girls' education in the country remains low with lower probabilities of girls finishing primary school. Girls who are married before the age of 15 years are more likely to be illiterate and less likely to be enrolled in school. Only $12 \%$ of married girls aged 15-19 years are enrolled in school compared to 60\% of unmarried girls. In Egypt and Ethiopia, nonetheless, boy child education is preferred to girl child education.

In Mali, schooling is free and compulsory for children between the ages of 7 and 16 years. However, primary school net enrolment rates in Mali remain some of the lowest in the world, growing from 44\% in 1999 to $61 \%$ in 2015 (UNESCO Institute for Statistics, 2016). This means that the number of children of primary school age that are enrolled in primary school is a little over half of the population of children who are of primary school age. While this percentage is more than half of the population of children, the number is still low in comparison to other countries. There are also marked gender disparities; the percentages of girls enrolled in primary and secondary education in 2011 were respectively $46 \%$ and $39 \%$, with a $10.37 \%$ completion rate for girls in lower secondary education in 2006, which increased by less than 3 percentage points over the subsequent decade $(13.15 \%$ in 2016). ${ }^{44}$ Because of the poor rates of school attendance and transition to secondary school, less than half of young people in Mali (aged 15-24 years) are literate ${ }^{45}$. This leads to increased vulnerability to child marriage. Mali's adult literacy rate is $33.4 \%$, which is a very low percentage for the country in comparison to other African countries ${ }^{46}$. This means that the majority of the population of Mali cannot read or write. This characterizes them as low-skilled workers since they are not would not be able to effectively perform jobs that require skilled labour.

An analysis of the levels of education for females revealed a clear effect and linkage to child marriage. In the countries with the highest prevalence of child marriage such as Niger, over $90 \%$ of girls married before 15 years have little or no formal education at all. There was a clear relationship between early marriage and level of education - those who marry late tend to have more education. The Table below summarizes the link between formal education and age of first marriage. 
Table 1: Distribution of Age at first marriage versus education level

\begin{tabular}{|c|c|c|c|c|c|c|c|}
\hline \multirow[b]{2}{*}{ Country } & \multirow[b]{2}{*}{$\begin{array}{l}\text { Age at first } \\
\text { marriage }\end{array}$} & \multicolumn{4}{|c|}{ Highest educational level } & \multirow[b]{2}{*}{$\begin{array}{c}\text { Number of } \\
\text { Women }\end{array}$} & \multirow[b]{2}{*}{ Source } \\
\hline & & $\begin{array}{c}\text { No } \\
\text { education }\end{array}$ & Primary & Secondary & Higher & & \\
\hline \multirow{3}{*}{ Tanzania } & $<=15$ & $42.6 \%$ & $54.6 \%$ & $2.8 \%$ & $0.0 \%$ & 7338 & \multirow{3}{*}{$\begin{array}{c}\text { DHS 2015- } \\
2016\end{array}$} \\
\hline & $16-17$ & $23.9 \%$ & $69.1 \%$ & $7.0 \%$ & $0.0 \%$ & 9705 & \\
\hline & $18-49$ & $18.6 \%$ & $63.9 \%$ & $16.8 \%$ & $0.7 \%$ & 19246 & \\
\hline & & & & & & & \\
\hline \multirow{3}{*}{ Nigeria } & $<=15$ & $70.2 \%$ & $18.4 \%$ & $10.6 \%$ & $0.8 \%$ & 3392 & \multirow{3}{*}{ DHS 2013} \\
\hline & $16-17$ & $50.3 \%$ & $24.1 \%$ & $23.4 \%$ & $2.2 \%$ & 1613 & \\
\hline & $18-49$ & $20.5 \%$ & $20.7 \%$ & $42.8 \%$ & $16.0 \%$ & 3653 & \\
\hline & & & & & & & \\
\hline \multirow{3}{*}{ Niger } & $<=15$ & $91.5 \%$ & $7.5 \%$ & $1.1 \%$ & $0.0 \%$ & 26579 & \multirow{3}{*}{ DHS 2012} \\
\hline & $16-17$ & $83.8 \%$ & $11.7 \%$ & $4.5 \%$ & $0.0 \%$ & 9375 & \\
\hline & $18-49$ & $71.1 \%$ & $13.1 \%$ & $13.6 \%$ & $2.1 \%$ & 8107 & \\
\hline & & & & & & & \\
\hline \multirow{3}{*}{ Mozambique } & $<=15$ & $40.8 \%$ & $52.9 \%$ & $6.3 \%$ & $0.0 \%$ & 10479 & \multirow{3}{*}{ DHS 2011} \\
\hline & $16-17$ & $37.5 \%$ & $54.8 \%$ & $7.6 \%$ & $0.1 \%$ & 8708 & \\
\hline & $18-49$ & $39.2 \%$ & $47.7 \%$ & $11.6 \%$ & $1.6 \%$ & 17506 & \\
\hline & & & & & & & \\
\hline \multirow{3}{*}{ Morocco } & $<=15$ & $88.2 \%$ & $9.9 \%$ & $1.8 \%$ & $0.0 \%$ & 8154 & \multirow{3}{*}{ DHS 2003-04 } \\
\hline & $16-17$ & $82.9 \%$ & $12.5 \%$ & $4.5 \%$ & $0.1 \%$ & 7700 & \\
\hline & $18-49$ & $70.3 \%$ & $13.3 \%$ & $13.0 \%$ & $3.4 \%$ & 16640 & \\
\hline & & & & & & & \\
\hline \multirow{3}{*}{ Mali } & $<=15$ & $87.0 \%$ & $9.3 \%$ & $3.6 \%$ & $0.1 \%$ & 12887 & \multirow{3}{*}{ DHS 2012-13 } \\
\hline & $16-17$ & $84.7 \%$ & $8.5 \%$ & $6.7 \%$ & $0.1 \%$ & 7290 & \\
\hline & $18-49$ & $83.1 \%$ & $8.0 \%$ & $8.1 \%$ & $0.8 \%$ & 13379 & \\
\hline \multirow{3}{*}{ Malawi } & $<-15$ & 2620 & 6850 & $50 \%$ & 010 & 17008 & \multirow{3}{*}{ DHS 2015-16 } \\
\hline & $16-17$ & $\begin{array}{l}20.2 \% \\
17.0 \% \\
\end{array}$ & $\begin{array}{l}00.5 \% \\
73.8 \% \\
\end{array}$ & $\begin{array}{l}5.2 \% \\
8.9 \%\end{array}$ & $\begin{array}{l}0.1 \% \\
0.3 \%\end{array}$ & $\begin{array}{l}17908 \\
19249\end{array}$ & \\
\hline & $18-49$ & $18.4 \%$ & $57.2 \%$ & $21.9 \%$ & $2.6 \%$ & 29895 & \\
\hline & & & & & & & \\
\hline \multirow{3}{*}{ Ethiopia } & $<=15$ & $77.2 \%$ & $19.1 \%$ & $2.8 \%$ & $0.9 \%$ & 19030 & \multirow{3}{*}{ DHS 2016} \\
\hline & $16-17$ & $72.3 \%$ & $21.7 \%$ & $4.5 \%$ & $1.5 \%$ & 9119 & \\
\hline & $18-49$ & $68.2 \%$ & $20.1 \%$ & $7.1 \%$ & $4.6 \%$ & 13065 & \\
\hline & & & & & & & \\
\hline \multirow{3}{*}{ Egypt } & $<=15$ & $59.0 \%$ & $19.2 \%$ & $21.4 \%$ & $0.4 \%$ & 9256 & \multirow{3}{*}{ DHS 2014} \\
\hline & $16-17$ & $39.5 \%$ & $17.0 \%$ & $42.4 \%$ & $1.1 \%$ & 11022 & \\
\hline & $18-49$ & $20.3 \%$ & $8.9 \%$ & $54.6 \%$ & $16.3 \%$ & 38988 & \\
\hline \multirow{3}{*}{ DR Congo } & $<=15$ & $266 \%$ & $513 \%$ & $219 \%$ & $01 \%$ & 17905 & \multirow{3}{*}{ DHS 2014} \\
\hline & $16-17$ & $21.1 \%$ & $48.3 \%$ & $30.2 \%$ & $0.4 \%$ & 14934 & \\
\hline & $18-49$ & $23.5 \%$ & $40.1 \%$ & $34.6 \%$ & $1.8 \%$ & 25242 & \\
\hline
\end{tabular}

Case Study 4: Drivers of child marriage in DRC

An estimated $70 \%$ of the population lives under the poverty line with inequality widening over a long period. Though the practice of child marriage stems out of traditional practices and not from religion, child marriage is associated with wealth creation for the girl's family usually given in the form of bride price. Poverty has enslaved households to the extent that debts either from business or household are settled using children who are 'given' as 'debt settlement' and thereafter are treated as wives. Sex slavery is also practiced in the mining zones in Eastern Congo with militia taking charge of the villages. Illiteracy also contributes to child marriage with statistics indicating that $50 \%$ of women aged 20-24 years with primary education were married before 18 years. Sexual violence continues to be used as a weapon of war by the all-powerful combatants. The lack of enforcement in addressing gender violence has resulted in adoption of the culture of impunity.

Source: UN Women field data (2018)

2.1.9 Stigma for those unmarried persists

In all the ten countries of study, the stigma associated with being unmarried or being unable to marry was pervasive 
and evident. Being unmarried by late adolescence or early-twenties was viewed negatively by adolescents and adults alike and believed to be linked to mental illness or social deficiency. As a result, there remains great cultural and social pressure to ensure girls did not lose their opportunities for marriage by waiting too long.

Respondents and key informants from all the ten countries of study shared how they worry if girls were not married early, like other girls. They mentioned that the girls end up being called names and fear that they will not ever marry anyone. They further mentioned that the girls would not want anything that could embarrass the clan or the family, so in fear of all that their parents actively look for men for the girls.

The respondents further confirmed that where a daughter is twenty years old and is not married, it is bad because she will be desperate and go with any man. On the other hand, when a boy is thirty years and hasn't married, they say he is abnormal, is cursed, and cannot produce. Worse of all is that the parents regret giving birth to such children, thereby removing the first line of support for any child.

\subsection{Logic and Pathway of Ending Child Marriage in Africa}

The diagram below summarizes the child marriage logic and theory of change causality and effects in Africa.

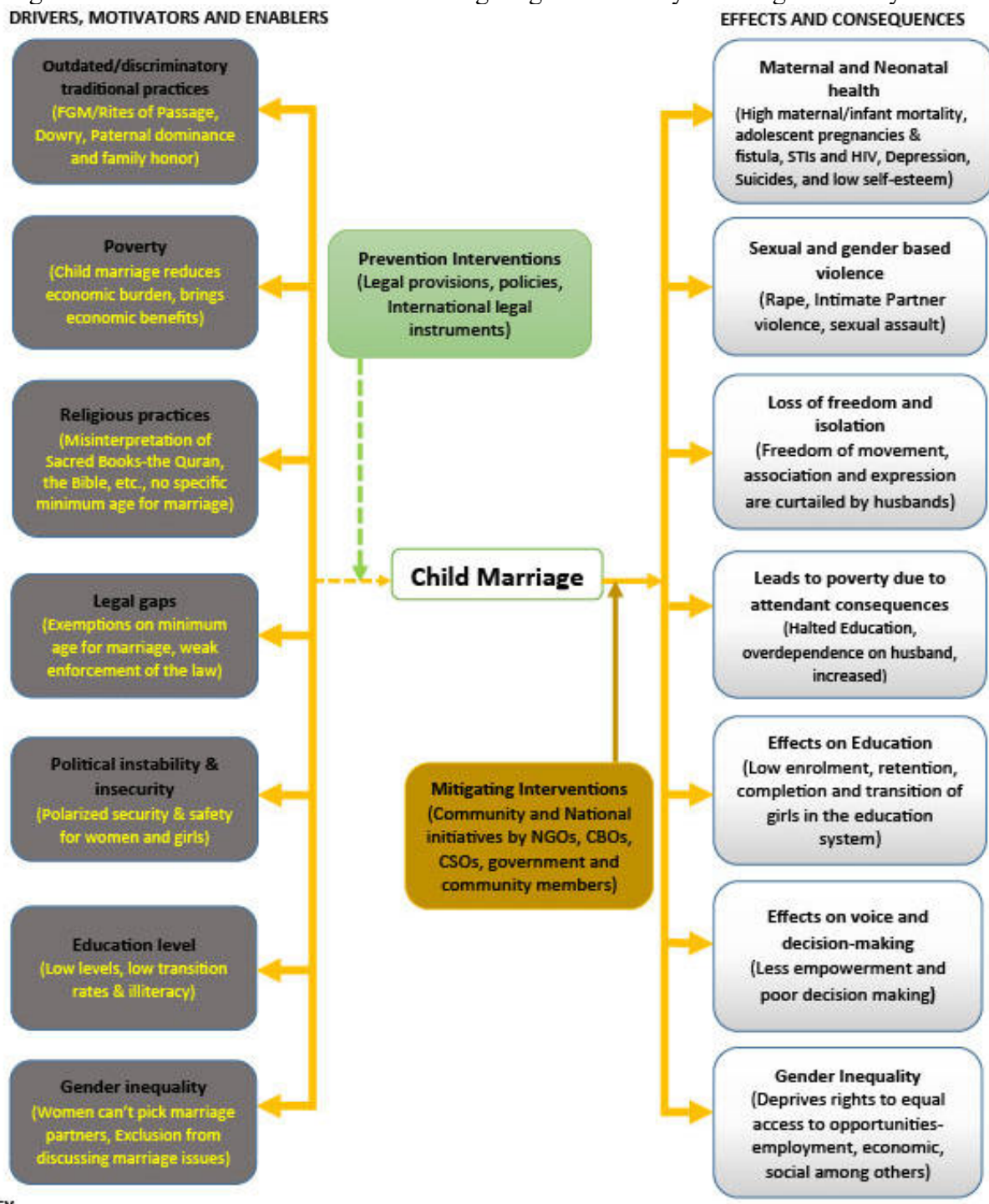

KFY

Legal Provisions - Include respective country Constitution, Acts of Parliament, and Executive/Court order

International Legal instruments - These include UN declarations and conventions such as UN Convention on the Rights of the Child (UNCRC) Regional Legal instruments - Include Africa African Charter on the Rights and Welfare of the Children, African Union Campaign to End child Marriage, etc.

Figure 5: Logic and Pathway of Change for Child Marriage in Africa

Source: UN Women field data (2018)

From figure 5: Logic and Pathway of Change for Child Marriage in Africa, the study views persistence of 
child marriage as a composite outcome of social, cultural, economic and religious' drivers, accompanied by low levels of education and gender inequalities. The drivers find fertile ground in the inadequacies/gaps in the policy and legal instruments, deficient enforcement and implementation of existing laws and policies. The situation is compounded by lack of political goodwill and committed leadership; as well as insecurity and weak policing of child and gender rights.

Overall, the causes and drivers of child marriage can be viewed as consisting of drivers and enablers all producing certain consequences in the lives of women and girls. They are moderated by preventive initiatives which constitute policy and laws of those countries backed by mitigating interventions including community, national and regional initiatives that respond positively to the needs and aspirations of women and girls. Enablers create the environment within which drivers can thrive while preventive and mitigating variables disable/ inhibit/ prevent and/ or slow down the increase of child marriage and contribute meaningfully to ending child marriage or, in their absence create a space for an accelerated surge in child marriage.

The study recognizes that community, national, regional and global initiatives can be a very useful tool in developing a coordinated picture of the roles of different stakeholders in a comprehensive response to child marriage. However, initiatives only add value if there has been sufficient planning and involvement of relevant stakeholders including the community, women and girls in particular, and if there are necessary resources, commitment and capacity to allow for implementation. This logic and theory of change affirms that it is necessary for stakeholders and African governments to develop related action plans on child marriage with monitoring and accountability mechanisms across different sectors. They should also ensure that national strategies and action plans are implemented across sectors - costed and budgeted for implementation with adequate planning, coordination and implementation. This must be coupled with priorities for interventions prioritizing the "do no harm approach" and those which will maximize impact and measure progress in the medium to long-term. This logic premises that addressing negative cultural and gender stereotypes and practices coupled with effective policy/legal environments at multiple levels is a prerequisite to ending child marriage in Africa.

The study notes that enablers, motivators and drivers work in concert to activate each other. In the hotspot communities amongst the study countries, they are able to combine well because of insufficient investment in policy and legal enforcement mechanisms and processes due to local and national politics, where allegiance may be torn between the laws and traditions. Limited investments enable lax enforcement of the laws and policies and thus it becomes an enabler. Furthermore, the absence of effective and functional monitoring, accountability and information systems from the national to local levels makes it difficult to keep track of the implementation, enforcement and transgression of existing interventions, laws and policies against child marriage. In the countries of study, the push factors - enablers, motivators and drivers of child marriage - are enhanced by gender inequality, weak and uncoordinated implementation of interventions, laws/policies and ineffective enforcement of laws/policies due to loopholes that encourage flexibility in adherence. Corruption, politics and violence, especially against women and girls, make it difficult to enforce existing laws/policies by discouraging reporting of cases, prosecution and deterrent punishment of perpetrators.

The absence of effective and functional monitoring, accountability and information systems from the national to local levels makes it difficult to keep track of the implementation, enforcement and transgression of existing laws and policies against child marriage.

4.0 Implications and Recommendations for Mitigating the Causes and Drivers of Child marriage in Africa Addressing the causes and drivers of child marriage is a sure strategic approach to promoting girl's and women's rights and thereby empowering them in areas such as quality education, good health, freedom from violence, work, as well as participation in the public life. In order to achieve this, it is critical that all stakeholders -government officials, international organizations, community and religious leaders, traditional leaders and cultural institutions, healthcare workers, school administrators and teachers, the police, the judiciary, the prosecutors, media parents, gender advocates as well as boys and girls - not only understand but also commit to their respective roles in eliminating child marriage.

This paper therefore makes the following recommendations to mitigate the causes and drivers of child marriage, which have been limited to the cases and drivers discussed. The paper is conscious that the causes range from cultural, religious, to policy and regulatory frameworks and the socio-ecological model. A number of recommendations that relate to those specific issues have been discussed in separate paper series for the study which relate to interventions, policy, challenges, effects and consequences and common manifestations. The following are the key recommendations of the paper which compliment those covered in the other paper series from the study:

i. Integrating child marriage prevention and response into gender-based violence programming: All programmes related to sexual and gender-based violence should include child marriage as a critical 
component. The study countries are encouraged to promote more equitable societies that are safer for women and girls through laws and policies related to inheritance, asset ownership, economic entitlement, and family law. When and where laws exist and are violated, girls need access to justice through legal -aid and paralegal professionals who are educated on the issue of child marriage and the needs of married adolescents.

ii. Develop an integrated engagement strategy and framework with traditional leaders and cultural institutions: Ending child marriage requires the collaboration and leadership of traditional leaders (widely regarded as gate keepers) who can harness the positive aspects and practices in culture and customs towards enhancing and enforcing the appropriate laws and policies. Working with traditional leaders and cultural institutions ensures a multifaceted approach in providing an enabling environment for change, accompanied by other reform strategies that encourage positive change in communities through proposed alternative rites of passage. This will enhance and leverage existing legislative and policy frameworks which are equally important in ending child marriage. Evidence has confirmed that working with traditional leaders and cultural institutions to challenge gender inequalities has a positive impact on the health and well-being of women and girls. It is therefore critical to engage them in ending child marriage through engagement in gender equality interventions, policy development and programming.

iii. The effect and utility of religious and cultural practices on child marriage: The place of religion in the child marriage agenda is ambiguous - it is both a driver and a potential intervention factor. The study established significant potential for the utility of religious interventions in the elimination of child marriage because there is a growing convergence between traditional and religious norms in most of the countries' hotspot communities. Cultural practices that are contradictory to religious practices tended to find common ground where both claimed moral purity as their ultimate focus in supporting child marriage. Because of this ambiguous and problematic relationship, the study recommends the establishment of robust inter-religious interventions working groups both at national and regional level. The study also recommends a regional research agenda on the place, role and strategic utility of the religion-traditions culture nexus in relation to child marriage. Religious leaders are encouraged to initiate within religious dialogue circles to question the long-held perspective of child marriages as being acceptable. In the words of Sheik Bashir, the concept of maturity for a girl in marriage should not only be based on her physical development but should also consider her mental, emotional and spiritual maturity. Dialogue within the religious circle should help create opportunities for greater awareness and understanding of the disadvantages of child marriages especially in light of the girl's opportunities for education and personal development. Emphasis should be placed on the benefits flowing from educating the child and the opportunities this will bring at the household, community and national levels.

iv. Behavioural interventions, agency and male involvement on ending child marriage: In all the countries studied, a clear gender-divide emerged: women and girls are victims while males are predominantly perpetrators and decision makers in child marriage. To lead transformation, there is need for robust sensitization and awareness creation to trigger change of behaviour in both males and females. Thus, the study recommends design and implementation of standardized, gender responsive, do no harm and context responsive evidence-driven interventions that can enhance the agency of girls while at the same time, educating males on the negative effects of child marriage and building on male responsibility and accountability. There is need to scale up and reinforce traditional complementary ways of redress and justice within national law enforcement and justice systems. Through regional technical forums, a male involvement strategy should be developed and integrated with/into the behaviour change interventions.

v. The use of media in engaging community to change harmful social norms: Efforts aimed at changing family and community attitude towards child marriage require massive campaigns to reach as many people as possible. Communities across the continent have no choice but to engage young people to educate them about the dangers of girls marrying under the age of 18 years. According to respondents in the 10 countries, it was established that the use of extensive communication via media including social media has great impact in informing and offering real support for change designed to eradicate child marriage in Africa and beyond. The findings further indicated that use of mass media can strengthen awareness of the general laws and policies pertaining to child marriage particularly among the public which is often less informed on such issues. Additionally, respondents pointed out that mass media campaigns and strategies have been instrumental in capturing governments' and other policy making bodies' attention on issues regarding child marriage including exerting pressure for policy and legislative changes in most countries.

vi. Community-based child protection and rights strategies: These should be intensified, and existing ones should be strengthened to ensure that there is systematic prevention, reporting and monitoring of child and forced marriages as well as providing support to children who have experienced child marriage. There is a need to recognize traditional, culture and religious institutions as part of the multi sectoral referral system in responding to child marriage and abuse. Case studies in the study have shown how effective community initiatives can be in eradicating harmful practices that perpetrate child marriages. Functional committees made 
up of religious leaders, local administrators and traditional leaders and cultural institutions should initiate and fast-track dialogue with communities that are still stuck into this practice. Child protection players should pool information, initiate and promote community-based child protection strategies, share their challenges and achievements towards improved communication and organization. There should be an intensified effort on heightening adolescent economic livelihoods and negotiation skills while addressing the roots and the harmful effects of child marriage. Child marriage interventions should identify adolescent girls as the prime recipients of development initiatives. Both boys and girls should be educated to ensure that they are enlightened enough to postpone marriage and denounce child marriage in their communities. Further, good practices like working community bylaws should be scaled up and replicated across Africa to increase the positive impact of the role of traditional leaders and cultural institutions in ending child marriage at community level.

vii. The education system needs strengthening to improve access, enrolment, retention and completion of school by girls with special efforts to reduce the wide gender gaps that continuously disadvantage the girl child: Enrolment, retention, completion and transition rates for girls need to be improved by committing the resources necessary to guarantee access to free, compulsory primary and secondary education for all girls and boys. Efforts such as making the school environment friendly for girl children and that help the keep the child in school need to be enhanced. At the same time, the government owes it to the citizens to improve the standards and quality of education to make it more attractive for many families to send their girls to school. This could be achieved through building more schools in rural areas to reduce the walking distance to school. Return to school policy for young/teenage mothers, making it easy for them to transfer to other schools, to minimize stigma and discrimination, needs to be encouraged and made more attractive for more girls to take up this opportunity. Additionally, this research supports anecdotal information that education can help to mitigate risk of child marriage. As education interventions are rarely implemented solely for child marriage outcomes, it remains challenging to prove this link, but it is one of the main recommendations to operationalize. In the 10 countries, education is key for economic empowerment of girls so as to improve their opportunities for better income, hence better livelihoods and in turn to address poverty as the leading driver of the practice of child marriage. Education further provides girls a safe space where they can articulate their issues and concerns and also learn from others about the dangers associated with child marriage, and generally go through the natural motions of growing up without simultaneously carrying the burdens of reproductive and productive roles. The return to school policies such as those in DRC, Malawi and Mozambique need to be encouraged as they ensure more girls get opportunities to explore on their potential for better future. Stakeholders are encouraged by the study to create non-monetary and monetary incentives, and/or to provide public social transfers for school attendance. Incentives can range from covering transportation costs, to covering school fees, to giving cash transfers for attendance, to providing hot meals. These will serve to reduce cases of child marriage.

viii. Strengthen support services to girls at risk and victims of child marriage: by developing the capacity of local organizations and governmental social welfare agencies to provide adequate, timely and quality services to mitigate the impact of child marriage on young girls and boys by protecting girl brides and grooms. This will not only require resourcing by government and other stakeholders but also improvement of referral systems and case management systems for prevention and response on issues of child marriage at community and national level.

ix. Actively engage girls in all decisions affecting them especially regarding investments, programming and policies on gender equality, Sexual and Reproductive Health and Rights in general and child marriage in particular: The study has established that it is imperative to effectively engage girls and young women in major discussions and decisions that affect them directly or indirectly such as those about child, early and forced marriage and its underlying causes and consequences. This follows the fact that Africa and particularly the study countries have all ratified the $\mathrm{CRC}$ which they agreed to respect and promote. Accordingly, countries should create a safe, favourable and enabling environment for girls and young women's effective participation. Girls' voices have great power to break the silence about child marriage and to give real life evidence for making the case at national and international levels, engaging communities, political leaders and policy makers. Putting girls' voices at the centre of the desired social change ensures transformational change that addresses the needs of girls. It also showcases girls' own initiatives and interventions in ending child marriage as active participants.

$x$. Community sensitisation and awareness on existing laws and policies: All ten study countries have enacted laws against child marriage and their citizenry and communities need to be educated on the content and spirit of the laws with emphasis on understanding the effects of the practice, corresponding punitive action for non-compliance, as well as protection mechanisms for girls in marriage who seek dissolution of marriage. Such education should be presented in user friendly formats including the development of reader friendly material translated into local languages. Further the initiatives must be deliberate, government-led and with 
involvement from religious and cultural leaders. Appropriate modes of communication may include social media platforms and other informative, educative and communication materials.

xi. On policy and legislation, there is need to laws and policies in Africa countries to reflect the globally accepted age of marriage and avoid loopholes for breach of law, strengthen law and policy enforcement mechanisms, strengthen prosecution and judicial systems and processes to ensure confidence in reporting and to provide deterrents amongst perpetrators, strengthen registration and vital statistics to ensure legal compliance to eliminate child marriages and develop national and regional accountability frameworks and mechanisms on ending child marriage in Africa.

\section{Acknowledgement}

The paper has been developed for UN Women East and Southern Africa by;

1. Sadiq Ahamad Jilani Syed-Regional Programme Manager-Ending Violence Against Women and GirlsUN Women East and Southern Africa Regional Office.

2. Jack Onyisi Abebe-Regional Knowledge Management and Research Specialist-UN Women East and Southern Africa Regional Office.

3. Michael Faraday Awino-Regional Knowledge Management and Research Assistant- UN Women East and Southern Africa Regional Office.

\section{References}

${ }^{1} \mathrm{UN}, 1989$. The Convention of the Rights of the Child, Article 24.3. Available at: <www.unicef.org/crc/>. Currently, 193 countries - excluding Somalia, South Sudan and the United States - are party to the Convention.

2 Ibid.

3 Ibid.

${ }^{4}$ UNFPA, 2013

5 The World Bank: Educating girls, ending child marriage; 2017

${ }^{6}$ Girls Not Brides, 2017.

${ }^{7}$ The 10 countries with the highest prevalence of child marriage in 2014 include Nepal, Burkina Faso, Ethiopia, India, Central African Republic, Mali, Chad, Bangladesh and Niger.

${ }^{8}$ United Nations Children's Fund, Ending Child Marriage: Progress and prospects, UNICEF, New York, 2014.

${ }^{9}$ UNICEF, 2017

${ }^{10}$ www.Devinfo.info/mdg5b/profiles/2017

${ }^{11}$ Source: https://www.girlsnotbrides.org/region/sub-saharan-africa/ - (cited on 14/01/2018)

12 UNICEF, 2017. Achieving a Future without Child Marriage: Focus on West and Central Africa. (Source: https://data.unicef.org/wp-content/uploads/2017/10/Child-Marriage-WEB.pdf

${ }^{13}$ UNICEF, 2017.

${ }^{14}$ Retrieved from https://eujournal.org/index.php/esj/article/view/1161 on 2018-01-2

${ }^{15}$ Report titled as 'the National Survey on the Drivers and Consequences of Child Marriage in Tanzania - Final Draft of $2^{\text {nd }} \quad J u l y$ 2016. Accessed on $19^{\text {th }}$ March 2018 from: http://www.cdftz.org/files/ChildMarriageinTanzaniaSurvey.pdf- The survey was carried out in 10 regions including Shinyanga, Tabora, and Dar es Salaam.

${ }^{16}$ Namely, the Policy Research for Development (REPOA); the Children's Dignity Forum (CDF); the United Nations Population Fund (UNFPA); the Plan International; and, the Foundation for Women Health Research and Development (FORWARD).

${ }^{17}$ Pazvakavambwa, B and Wanjau, C (2015) Preliminary Research into the Extent, Factors and Effects of Child Marriage Research in Zambia, Zimbabwe and Malawi

18 ibid

${ }^{19}$ Cynthia Gorney, The Secret World of Child Brides, National Geographic, June 2011, at 87.

${ }^{20}$ United States, Office to Monitor and Combat Trafficking in Persons. (2017). Trafficking in persons report. Retrieved from U.S. Department of State website: https://www.state.gov/documents/organization/271339.pdf

${ }^{21}$ UNICEF, 2015, Child Marriage and Adolescent Pregnancy in Mozambique: Policy Brief

${ }^{22}$ Supra Note 11

23 Surprising trends in child marriage in Ethiopia, UNICEF, March 2016 at Page 3. Available at https://www.unicef.org/ethiopia/Briefing.pdf, (last accessed on 27.1.2018)

${ }^{24}$ Retrieved from https://rlp.hds.harvard.edu/ on 2018-01-02

25 Ibid.

${ }^{26}$ Ibid.

${ }^{27}$ Ibid. 
${ }^{28}$ Ibid.

${ }^{29} \mathrm{https}$ //en.wikipedia.org/wiki/Religion_in_Tanzania

${ }^{30}$ ibid

${ }^{31}$ Supra Note 26

${ }^{32}$ Cynthia Gorney, The Secret World of Child Brides, National Geographic, June 2011, at 87.

${ }^{33}$ Bove, Vala-Haynes, and Valeggia, 2014. Polygyny and Women's Health in Rural Mali

${ }^{34}$ Plan WARO, 2014. Child Marriage in West Africa and Cameroon: A Desk Review.

${ }^{35}$ Ibid.

36 Surprising trends in child marriage in Ethiopia, UNICEF, March 2016 at Page 3. Available at https://www.unicef.org/ethiopia/Briefing.pdf, (last accessed on 27.1.2018)

${ }^{37}$ Ibid

${ }^{38}$ Ibid

39 UNICEF, 2015. Child Notice Morocco. Accessed at https://www.unicef.be/content/uploads/2016/06/cnmarokko-eng-def.pdf on 26 March 2018.

40 Aidan Lewis, 2011. BBC News: Why has Morocco's king survived the Arab Spring? Accessed at http://www.bbc.com/news/world-middle-east-15856989 on 3 March 2018.

${ }^{41}$ Ibid,

42 ibid

National

Education

Profile,

Malawi,

2014

(https://www.epdc.org/sites/default/files/documents/EPDC\%20NEP_Malawi.pdf)

${ }^{44}$ Centre for the study of African economies-July 2017.

$45 \mathrm{http}: / /$ www.our-africa.org/mali/education-jobs

${ }^{46} \mathrm{https}$ //developingmali.weebly.com/part-1.html 